\title{
Comparison of the fatty acid profiles of Borrelia, Serpulina and Leptospira species
}

\author{
M. Anne Livesley, Ian P. Thompson, Mark J. Bailey and Patricia A. Nuttall* \\ NERC Institute of Virology and Environmental Microbiology, Mansfield Road, Oxford OX1 3SR, UK
}

(Received 7 September 1992; revised 7 December 1992; accepted 14 December 1992)

\begin{abstract}
Fatty acid methyl ester (FAME) derivatives were examined as a means of characterizing Borrelia burgdorferi isolates and distinguishing them from other spirochaetes. Analysis was performed using a gas liquid chromatography column in conjunction with Microbial Identification System (MIS) software. Reproducible FAME profiles were produced which distinguished Borrelia species, Serpulina hyodysenteriae and Leptospira icterohaemorrhagiae. Furthermore, the FAME profiles of four recognized Borrelia species (including two American isolates of Borrelia burgdorferi, B31 and JD1) were distinct from one another and from the BSK II medium in which they were grown. The results confirm previous reports that FAME profiles of bacteria represent a diagnostic phenotypic property and suggest that they may have applications in the chemotaxonomic classification of Borrelia species.
\end{abstract}

\section{Introduction}

Many workers have attempted the physical and genetic characterization of the spirochaetes. Their cellular ultrastructure is unique amongst the eubacteria (CanaleParola, 1991) and they have several distinguishing features. The spirochaetal outer sheath has some features analogous to the outer membrane of Gram-negative bacteria and spirochaetes also possess internal periplasmic flagella which are organs of motility (Paster \& Canale-Parola, 1980). The number of flagella varies according to the spirochaete species (Paster et al., 1991). Spirochaetes are resistant to the antibiotic rifampin (Leschine \& Canale-Parola, 1986) and possess ornithine in their cell wall peptidoglycan (with the exception of the Leptospira) (Joseph et al., 1973).

Classification of spirochaetes has relied largely upon the use of genetic methods. rRNA oligonucleotide cataloguing has classified the spirochaetes into five major groups: Treponema, Spirochaeta, borrelias, leptospires and Treponema hyodysenteriae (Paster et al., 1984). Subsequently Treponema hyodysenteriae and Treponema innocens were reclassified in a new genus, Serpulina (Stanton et al., 1991). Recent work, using analysis of

*Author for correspondence. Tel. (0865) 512361; fax (0865) 59962.

Abbreviations: FAME, fatty acid methyl ester; MIS; microbial identification software. nearly complete $16 \mathrm{~S}$ rRNA sequences has divided the spirochaetes into six groups: treponemes, Spirochaeta, borrelias, a spirochaete strain isolated from a shrew, Serpulina and Leptospira species (Paster et al., 1991). Borrelia burgdorferi, the Lyme disease spirochaete, has been analysed at the phylogenetic level using DNADNA hybridization (Postic et al., 1990), 16S rRNA sequencing (Marconi \& Garon, 1992a,b) and multilocus enzyme electrophoresis (Boerlin et al., 1992). Such methods are complex and time-consuming and, by comparison, analysis of FAME profiles is a simpler technique when used in conjunction with the MIDI microbial identification system. The Leptospira have been analysed using fatty acid profiles as a key for their classification (Cacciopuoti et al., 1991; Moribayashi et al., 1991). In this study we have used fatty acid profiles to distinguish selected members of the spirochaete family and to investigate the possibility of using the relatedness of profiles as a tool for the classification of borrelias.

\section{Methods}

Culture of bacterial strains. Leptospira interrogans (serogroup icterohaemorrhagiae) was cultured in EMJH medium as originally described by Ellinghausen \& McCullogh (1965), $90 \%$ (v/v) EMJH base, $10 \%(\mathrm{v} / \mathrm{v})$ EMJH supplement, $0 \cdot 15 \%(\mathrm{w} / \mathrm{v})$ agar, $6 \%(\mathrm{v} / \mathrm{v})$ rabbit serum. The $0.15 \%$ agar and $6 \%$ rabbit serum were added immediately prior to use. The L. icterohaemorrhagiae were grown in $5 \mathrm{ml}$ cultures at $30^{\circ} \mathrm{C}$ for $7 \mathrm{~d}$. 
Serpulina hyodysenteriae (S75/1 and B78 isolates) was cultured as described by Kent et al. (1988). The medium used consisted of Trypticase Soy Broth (TSB) supplemented with $0.2 \%(\mathrm{w} / \mathrm{v})$ yeast extract, $0.25 \%(\mathrm{w} / \mathrm{v})$ glucose, $0.05 \%(\mathrm{w} / \mathrm{v})$ L-cysteine hydrochloride, $0.0001 \%(\mathrm{w} / \mathrm{v})$ resazurin and $800 \mu \mathrm{g}$ Spectam $\mathrm{ml}^{-1}(400 \mu \mathrm{g}$ soluble spectinomycin $\mathrm{ml}^{-1}$ ). The medium was autoclaved, purged with deoxygenated nitrogen, stored at $4{ }^{\circ} \mathrm{C}$ and used within $7 \mathrm{~d}$ of preparation. Before use, the medium was supplemented with $0.2 \%$ $(\mathrm{w} / \mathrm{v})$ sodium bicarbonate and $10 \%(\mathrm{v} / \mathrm{v})$ rabbit serum, under a stream of deoxygenated nitrogen with $5 \%(\mathrm{v} / \mathrm{v})$ carbon dioxide. The $S$. hyodysenteriae were incubated in $2 \mathrm{ml}$ cultures for $3-4 \mathrm{~d}$ at $37^{\circ} \mathrm{C}$ then transferred to $50 \mathrm{ml}$ cultures for a further $3-4 \mathrm{~d}$.

Borrelia species were grown in a modified Barbour-Stoenner-Kelly medium as described by Barbour (1984). The medium contained bovine serum albumin fraction V (Boehringer) and CMRL 1066 without sodium bicarbonate and glutamine (Gibco). The media were sterilized using $0.22 \mu \mathrm{m}$ filters. Immediately prior to use, $10 \%(\mathrm{v} / \mathrm{v})$ rabbit serum and $20 \mathrm{ml} 7 \%(\mathrm{w} / \mathrm{v})$ gelatin per $100 \mathrm{ml}$ were added. The media were dispensed into $10 \times 100 \mathrm{~mm}$ tubes, where $6 \mathrm{ml}$ occupied approximately $75 \%$ of the volume available. The Borrelia were incubated at $34{ }^{\circ} \mathrm{C}$ until a cell density of $10^{8}$ organisms per $\mathrm{ml}$ was reached. The same batches of medium enrichment (CMRL 1066) were used in all experiments.

Spirochaetes were harvested by centrifugation $(1000 \mathrm{~g}, 15 \mathrm{~min})$ when grown to a highly motile condition as determined by dark field microscopy. Fifty milligrams (wet wt) of spirochaetes were required for each fatty acid profile. The spirochaetes were washed three times in phosphate-buffered saline ( $\mathrm{pH} \mathrm{7.4)}$ and finally resuspended in $0.2 \mathrm{ml}$ phosphate-buffered saline.

Fatty acid methyl ester extraction. Long chain fatty acids extracted from bacteria require derivatization before GLC. FAME derivatives were prepared using the following procedure (Kloepper et al., 1992): spirochaetes ( $50 \mathrm{mg}$, collected as described above) were saponified with $1 \mathrm{ml} 3.75 \mathrm{M}-\mathrm{NaOH}$ in $50 \%$ aqueous methanol by heating at $100{ }^{\circ} \mathrm{C}$ for $30 \mathrm{~min}$. Free fatty acids in the preparation were methylated with $2.0 \mathrm{ml}$ $6 \mathrm{M}-\mathrm{HCl}$ in methanol, heated at $80^{\circ} \mathrm{C}$ for $10 \mathrm{~min}$, followed by rapid cooling to room temperature. FAMEs were extracted from the aqueous phase with a 1:1 mixture of hexane and methyl t-butyl ether and the acidified lower phase discarded. The extract was washed and neutralized with $3.0 \mathrm{ml} 0.3 \mathrm{M}-\mathrm{NaOH}$, separation being aided by the addition of a few drops of saturated sodium chloride.

Gas liquid chromatography. FAMEs were analysed with a Hewlett Packard series II gas chromatography model $5890 \mathrm{~A}$ equipped with a $25 \mathrm{~m} \times 0.22 \mathrm{~mm} \times 0.33 \mu \mathrm{m}$ phenyl methyl silicone capillary column. Gas chromatographic runs and the integration parameters, retention time, elution order and percentage of the total area of the FAME peaks were recorded via a Hewlett Packard integrator. Samples were processed with the HP 360 benchtop workstation using the Microbial Identification System software (MIS) and MIDI (Newark, Delaware) which calibrates the gas chromatograph with a commercial mixture of straight-chain saturated and hydroxy FAMEs at the beginning of each analysis run and after every tenth sample [see Stead et al. (1992) for a description of typical conditions]. A library for the spirochaetes was constructed based on three replicates per isolate.

Reproducibility of FAME analysis. The reproducibility of FAME profiles for all the samples analysed was determined by analysing each isolate three times under standard conditions. For each peak in the chromatogram the coefficient of variation (standard deviation/ mean) $\times 100$ was calculated (Mukwaya \& Welch, 1989). Peak area values for each fatty acid were calculated as percentages of the total peak area to eliminate the effect of inoculum size variation. MIs includes a statistical facility for the generation of dendrograms which groups bacteria (samples) according to the qualitative and quantitative relatedness of FAMEs. Similarity and relatedness are expressed as Euclidian distance values, as defined by Austin \& Priest (1986). The fatty acid profile for Pseudomonas aureofaciens was obtained from the MIDI library as described by Thompson et al. (1992).

\section{Results}

Representative FAME profiles for $L$. icterohaemorrhagiae, $S$. hyodysenteriae, B. burgdorferi, B. hermsii, $B$. turicatae and $B$. parkeri are shown in Fig. 1. The FAME profile of $L$. icterohaemorrhagiae is similar to that published by Cacciopuoti et al. (1991).

In $L$. icterohaemorrhagiae, 26 peaks were recognized as typical of this isolate, of which 4 peaks had areas equal to or greater than $3 \%$ of the total percentage FAME area, and these peaks were identified using the MIDI system. In S. hyodysenteriae, a total of 21 peaks were recognized as typical of FAME profiles on the basis of their presence in replicates of the two isolates used in this study. Peak areas equal to or greater than $3 \%$ of the total percentage FAME area in at least one isolate were used in further analysis. Eight peaks had values above the cutoff point in the isolates tested and these peaks were identified using MIDI. A total of eight peaks were recognized as typical of Borrelia burgdorferi on the basis of their presence in repeated samples of the two isolates used in this study.

FAME peaks which had areas equal to or greater than $3 \%$ of the total FAME percentage area between S. hyodysenteriae, L. icterohaemorrhagiae and Borrelia species are compared in Table 1 . Fatty acids present in $L$. icterohaemorrhagiae, $S$. hyodysenteriae (S75/1 isolate) and $B$. burgdorferi (B31 isolate) are shown in Table 2. Coefficients of variation were calculated between replicates and were found to be less than or equal to 7.52 for fatty acids present at greater than or equal to $3 \%$ of the total \% FAME area.

In view of the reports that Borrelia species scavenge fatty acids (Johnson et al., 1984), FAME profiles of fresh and 'spent' media (media in which B. burgdorferi had grown and then been removed) were analysed (Fig. 2) together with a representative $B$. burgdorferi profile (B31 reference strain, Fig. 1C). Different peaks (such as methyl tetradecanoate and parts of summed feature 6) occur in the $B$. burgdorferi profile than in the fresh and 'spent' media profiles, suggesting that $B$. burgdorferi can in fact modify fatty acids. Washings from the Borrelia were also analysed to check that fatty acids in the media were not adhering to the Borrelia.

The MIS software enabled a FAME relatedness tree to be constructed (Fig. 3). Clustering was accomplished by the unweighted pair group method for arithmetic averages (Sneath \& Sokal, 1973). This showed a clear distinction between the species investigated in this study. Inclusion of $P$. aureofaciens in the analysis as an 


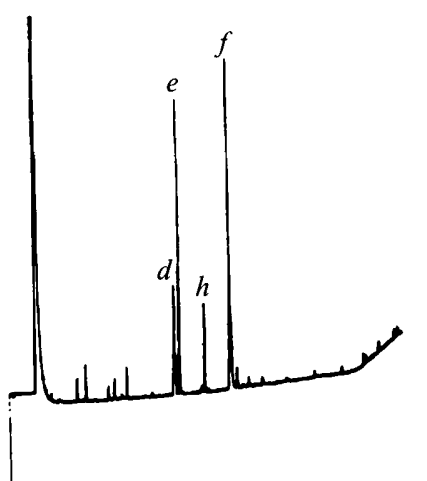

A

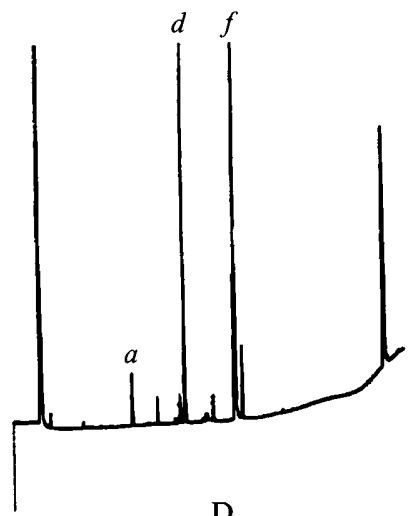

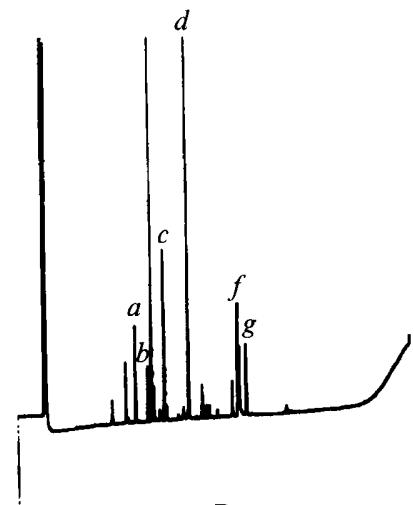

B

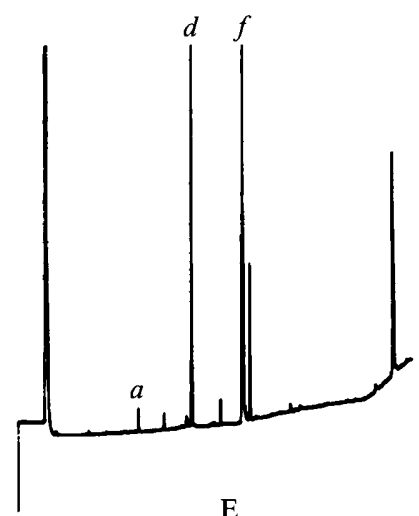

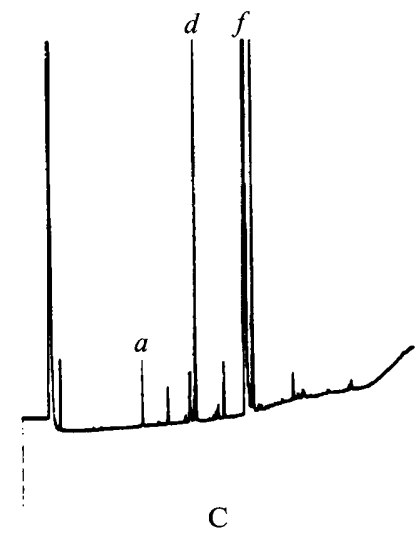

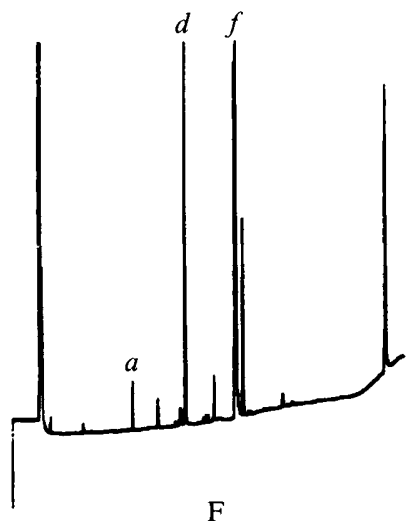

Fig. 1. Representative FAME profiles of: (A) Leptospira icterohaemorrhagiae; (B) Serpulina hyodysenteriae; (C) Borrelia burgdorferi: (D) Borrelia hermsii; (E) Borrelia turicatae; (F) Borrelia parkeri. Peaks labelled $a-h$ correspond to the fatty acids in Table 1.

Table 1. Comparison of the fatty acids present in Leptospira icterohaemorrhagiae, Serpulina hyodysenteriae and Borrelia species (greater than or equal to $3 \%$ of the total percentage FAME area)

The letter assigned to each fatty acid correlates with the peaks shown in Fig. 1.

\begin{tabular}{|c|c|c|c|c|c|}
\hline & Name & $\begin{array}{l}\text { Shorthand } \\
\text { Designation }\end{array}$ & $\begin{array}{c}\text { Leptospira } \\
\text { ictero- } \\
\text { haemorrhagiae }\end{array}$ & $\begin{array}{c}\text { Serpulina } \\
\text { hyodysenteriae }\end{array}$ & $\begin{array}{c}\text { Borrelia } \\
\text { species }\end{array}$ \\
\hline$a$ & Tetradeconoate & $\mathrm{C} 14: 0$ & & $x$ & $x$ \\
\hline$b$ & 13-Methyltetradecanoate & $\mathrm{C} 15: 0$ iso & & $x$ & \\
\hline$c$ & 3-Hydroxy-12-methyltridecanoate & $3-\mathrm{OH} \mathrm{i-14:0}$ & & $x$ & \\
\hline$d$ & Hexadecanoate & $\mathrm{C} 16: 0$ & $x$ & $x$ & $x$ \\
\hline$e$ & cis-Hexadec-9-enoate & $\mathrm{C} 16: 1(9 c)$ & $x$ & & \\
\hline$f$ & cis-Octadec-9-enoate & $\mathrm{C} 18: 1(9 c)$ & $x$ & $x$ & $x$ \\
\hline$g$ & Octadecanoate & C18:0 & & $x$ & \\
\hline$h$ & Methylenehexadecanoate & C17:0 cyclo & $x$ & & \\
\hline
\end{tabular}

'outgroup' confirmed that the different spirochaete species formed a common cluster. The Euclidian distance can be used to estimate the taxonomic distances between the species used in the study. Thus the results indicate that $B$. turicatae and $B$. parkeri are more closely related to each other than they are to $B$. hermsii and that all three species show a closer evolutionary relationship than they do to B. burgdorferi. 
Table 2. Fatty acids present in the bacterial isolates used in this study

Figures are percentages of total FAME area $( \pm \mathrm{SD})$. A summed feature refers to a group of fatty acids not resolved by the procedure used in this study.

\begin{tabular}{|c|c|c|c|c|}
\hline Name & $\begin{array}{l}\text { Shorthand } \\
\text { designation }\end{array}$ & $\begin{array}{c}\text { Leptospira } \\
\text { ictero- } \\
\text { haemorrhagiae }\end{array}$ & $\begin{array}{c}\text { Serpulina } \\
\text { hyodysenteriae }\end{array}$ & $\begin{array}{c}\text { Borrelia } \\
\text { burgdorferi }\end{array}$ \\
\hline 3-Hydroxydecanoate & $3 \mathrm{OH} \mathrm{C10:0}$ & $1 \cdot 70 \pm 0 \cdot 81$ & & \\
\hline Dodecanoate & $\mathrm{C} 12: 0$ & $2.71 \pm 0.76$ & & \\
\hline 2-Hydroxydodecanoate & $2 \mathrm{OH} \mathrm{C} 12: 0$ & $1.01 \pm 0.92$ & & \\
\hline 3-Hydroxydodecanoate & $3 \mathrm{OH} \mathrm{C12:0}$ & $1.67 \pm 0.61$ & & \\
\hline Tridecanoate & $\mathrm{C} 13: 1$ & & $1.61 \pm 0.43$ & \\
\hline Unknown $\mathrm{C} 13$ & $\mathrm{C} 13$ & & $2 \cdot 09 \pm 0.81$ & \\
\hline Tetradecanoate & $\mathrm{C} 14: 0$ & $2 \cdot 61 \pm 0.65$ & $5.60 \pm 0.92$ & $3 \cdot 00 \pm 0 \cdot 22$ \\
\hline 3-Hydroxy-12-methyltridecanoate & $3 \mathrm{OH}$ i-14:0 & & $8 \cdot 68 \pm 2 \cdot 13$ & \\
\hline 2-Hydroxytetradecanoate & $2 \mathrm{OH} \mathrm{C14:0}$ & & $0.78 \pm 0.31$ & \\
\hline Pentadecanoate & C15:0 & & & $1.09 \pm 0.07$ \\
\hline 13-Methyltetradecanoate & $\mathrm{C} 15: 0$ iso & & $19 \cdot 29 \pm 4 \cdot 25$ & \\
\hline 12-Methyltetradecanoate & $\mathrm{C} 15: 0$ anteiso & & $1 \cdot 87 \pm 0.35$ & \\
\hline Hexadecanoate & $\mathrm{C} 16: 0$ & $25 \cdot 75 \pm 2 \cdot 21$ & $35.75 \pm 1.02$ & $58 \cdot 74 \pm 2 \cdot 28$ \\
\hline Hexadecenoate & $\mathrm{C} 16: 1$ & $2 \cdot 19 \pm 0.63$ & & \\
\hline cis-Hexadec-9-enoate & $\mathrm{C} 16: 1(9 c)$ & $10.54 \pm 0.53$ & $0.77 \pm 0.23$ & $1 \cdot 38 \pm 0 \cdot 24$ \\
\hline 3-Hydroxyhexadecanoate & $3 \mathrm{OH} \mathrm{C16:0}$ & & $2 \cdot 17 \pm 0 \cdot 62$ & \\
\hline Heptadecanoate & $\mathrm{C} 17: 0$ & & $0.50 \pm 0.04$ & \\
\hline 15-Methylhexadecanoate & $\mathrm{C} 17: 0$ iso & & $0.72 \pm 0.20$ & \\
\hline 14-Methylhexadecanoate & $\mathrm{C} 17: 0$ anteiso & & $0.74 \pm 0.09$ & $0 \cdot 37 \pm 0 \cdot 12$ \\
\hline Methylenehexadecanoate & C17:0 cyclo & $8.30 \pm 1.64$ & & \\
\hline Octadecanoate & $\mathrm{C} 18: 0$ & $1.93 \pm 0.94$ & $3.98 \pm 1.91$ & $2.79 \pm 0.69$ \\
\hline cis-Octadec-9-enoate & $\mathrm{C} 18: 1(9 c)$ & $32.09 \pm 1.03$ & $4 \cdot 54 \pm 1 \cdot 55$ & $23 \cdot 77 \pm 0.42$ \\
\hline Arachidonate & $\mathrm{C} 20: 4(5 c, 8 c, 11 c, 14 c)$ & & $0.44 \pm 0.24$ & \\
\hline Summed feature 2 & & & $2 \cdot 70 \pm 1 \cdot 35$ & \\
\hline Summed feature 5 & & & $1.89 \pm 0.06$ & \\
\hline Summed feature 6 & & $2.60 \pm 0.75$ & $6 \cdot 44 \pm 2 \cdot 08$ & $6 \cdot 07 \pm 0.43$ \\
\hline Summed feature 7 & & $5 \cdot 24 \pm 0.53$ & & \\
\hline Summed feature 9 & & $0 \cdot 83 \pm 0.12$ & & \\
\hline
\end{tabular}

\section{Discussion}

A fatty acid profile is a stable phenotypic expression of a bacterial genotype when the bacteria under study are grown in controlled culture conditions (Welch, 1991). Fatty acid metabolism is constitutive and directed by the chromosome and is not known to be under plasmid control. The presence of certain fatty acids in bacteria has been shown to correlate with taxonomic conventions (Drucker, 1976; Lechevalier, 1977). Hence the patterns of fatty acids, once identified, have resulted in the production of 'fingerprints' of bacteria. This has led to the use of FAME profiles as a key for chemotaxonomic classification (Cacciopuoti et al., 1991). Although fatty acid analysis has been used to classify Leptospira species (Cacciopuoti et al., 1991) it has not been applied to other spirochaetes. One possible reason for this may be, in the case of Borrelia species, that spirochaetes have typically been considered to 'scavenge' fatty acids rather than synthesize or modify fatty acids (Johnson et al., 1984). Although the FAME profiles of the Borrelia species used in this study do contain fatty acids present in the medium, they also contain novel fatty acids absent from the medium, suggesting that Borrelia species have the capacity to modify fatty acids, e.g. B. hermsii, B. parkeri and $B$. turicatae contain $>0.4 \%$ arachidonate $[\mathrm{C} 20: 4(5 c, 8 c, 11 c, 14 c)]$ which has a higher number of carbon atoms than any of the fatty acids present in BSK II medium. This is indicative of metabolism and synthesis although this fatty acid was not identified other than by retention time.

Borrelia species and $S$. hyodysenteriae contain many of the cellular fatty acids known to be present in $T$. pallidum and Leptospira species (Kondo \& Ueta, 1972; Matthews et al., 1979). In Leptospira, up to $50 \%$ of the cellular fatty acids are methyl hexadecanoate $(\mathrm{Cl} 16: 0)$, the remainder being unsaturated, whilst $T$. pallidum contains mainly methyl hexadecanoate, methyl octadecenoate (C18:1) and methyl octadecanoate (C18:0) (Welch, 1991). The major fatty acid components of the Borrelia species used in this study are methyl tetradecanoate (C14:0), methyl hexadecanoate and methyl cis-octadec9-enoate [C18:1(9c)]. In addition, minor variations in the fatty acid composition of the different Borrelia species studied were recorded. These 'fingerprints' of the Borrelia species may have an application for determining their genetic and taxonomic relationships.

The dendrogram in Fig. 3, based on FAME profiles, 


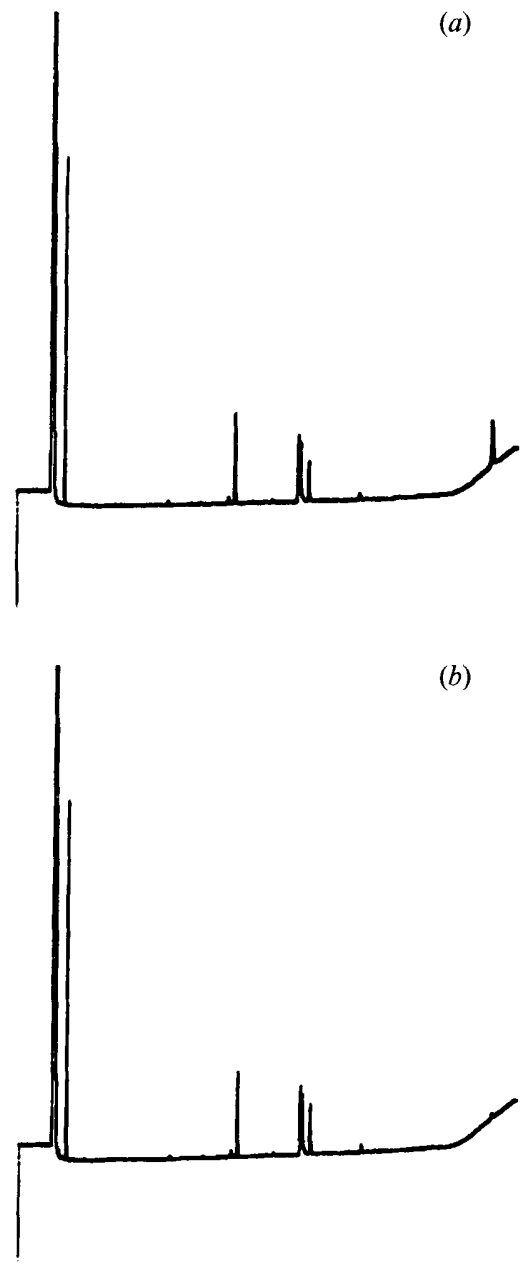

Fig. 2. FAME profiles generated on extracted cells and media analysed by GLC of ( $a$ ) BSK II medium (fresh) (b) 'spent' medium (supernatant collected by centrifugation of $B$. burgdorferi $\mathrm{B} 31$ cultures). shows the relatedness of the spirochaetes used in this study. Furthermore, from the data based on Borrelia species, FAME profiles can be used to distinguish Borrelia at the inter-species level (between B. parkeri, $B$. hermsii, B. turicatae and B. burgdorferi). Preliminary work with isolates of $S$. hyodysenteriae and $B$. burgdorferi suggests that FAME profile relatedness may be extended to distinguish isolates at the intra-species level (or intraspecies variation).

Interestingly, the two isolates of B. burgdorferi used in this study (B31 and JD1) cluster separately from the other Borrelia species, B. hermsii, B. turicatae and $B$. parkeri. A major difference between $B$. burgdorferi and the other Borrelias examined is shown in their tick vectors. Ticks of the ixodid species are vectors of $B$. burgdorferi, primarily Ixodes ricinus and I. hexagonus in Europe and I. dammini and I. pacificius in north America (Lane et al., 1991), whereas B. hermsii, B. turicatae and $B$. parkeri are transmitted by the argasid tick species, Ornithodoros hermsi, O. turicata and O. parkeri (Kelly, 1984). However, the taxonomic relationships of $B$. hermsii, B. turicatae and B. parkeri, based on FAME analysis, does not correspond with their known similarities in carbohydrate metabolism. $B$. turicatae ferments only glucose, raffinose and dextrin whereas $B$. hermsii and $B$. parkeri ferment glucose, maltose, trehalose, starch, dextrin and glycogen, but not raffinose (Kelly, 1984).

All typical Gram-negative bacteria contain endotoxins which are lipopolysaccharide (LPS)-containing compounds usually found in the outer envelope and which have been implicated in the pathogenesis of several diseases (Rietschel et al., 1982). Hydroxy fatty acids,

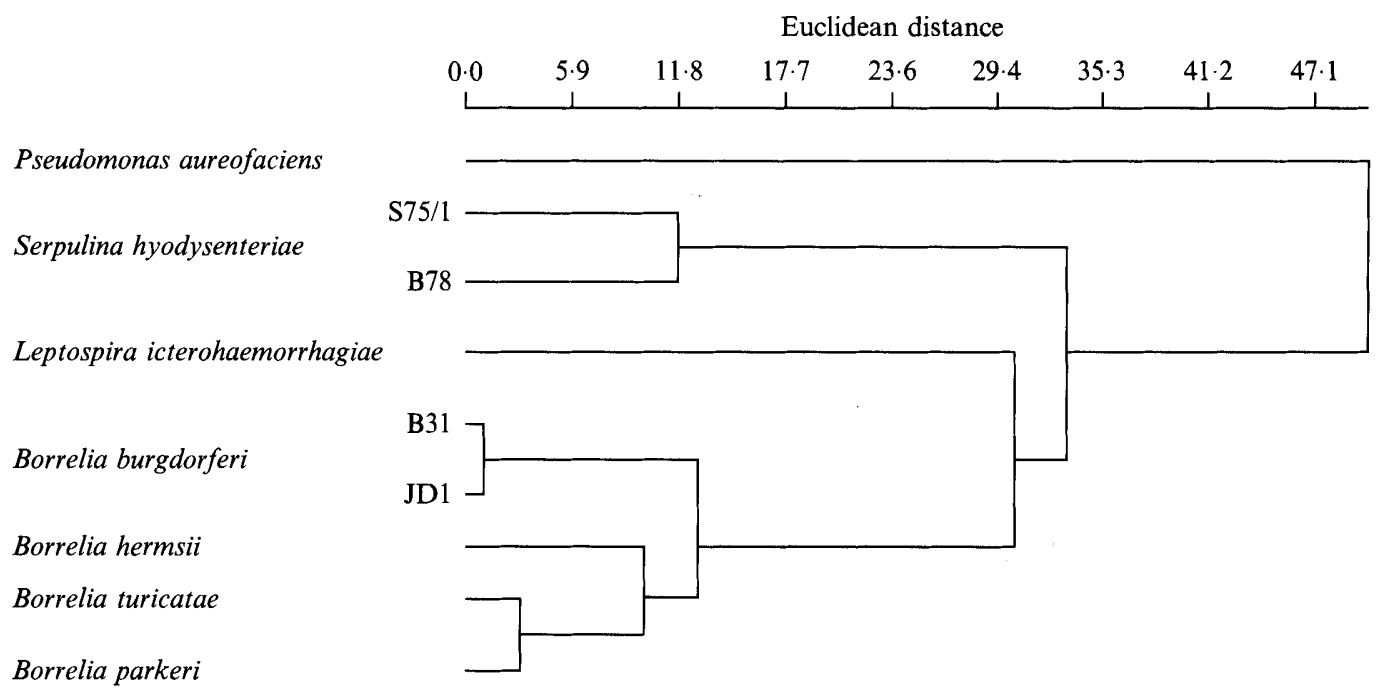

Fig. 3. Dendrogram of FAME profile demonstrating relatedness (Euclidian distance) of the species and isolates used in this study. 
particularly 3-hydroxymyristic acid, (3OH C14:0) are associated with LPS (Galanos et al., 1977). LPS has been found in L. interrogans serogroup copenhageni (Vinh et al., 1986) and also in S. (Treponema) hyodysenteriae (Nuessen et al., 1982; Bailey et al., 1985). Furthermore LPS from L. interrogans serogroup copenhageni has been shown to contain several hydroxy fatty acids $(3 \mathrm{OH}$ $\mathrm{C} 10: 0,3 \mathrm{OH} \mathrm{C12:0,} \mathrm{OH} \mathrm{C15:0,} \mathrm{2OH} \mathrm{C16:0,} \mathrm{OH} \mathrm{C17:0)}$ although no 3-hydroxymyristic acid was shown to be present (Vinh et al., 1986). Table 2 shows that hydroxylated fatty acids are present in $S$. hyodysenteriae and $L$. interrogans serogroup icterohaemorrhagiae, which is consistent with the presence of LPS is such organisms. By contrast, $B$. burgdorferi contains no hydroxylated fatty acids, which is consistent with the proposed absence of LPS from $B$. burgdorferi suggested by Takayama et al. (1987). Thus fatty acid analysis may provide a tool for analysis of the chemotaxonomy of the spirochaetes and for the study of fatty acids present in molecules conferring pathogenicity.

We thank Warren Thomas (Institute of Animal Health, Compton, Berkshire, UK) for the gift of $S$. hyodysenteriae cultures, Joanne Webster (Department of Zoology, University of Oxford) for the Leptospira interrogans serogroup icterohaemorrhagiae, Dr Daniele Postic (Institut Pasteur, Paris, France) for the B. hermsii, B. turicatae and $B$. parkeri. We thank the PHLS, Hereford for supplying the $B$. burgdorferi B31 isolate (ATCC 35210) and CDC, Fort Collins, USA for the $B$. burgdorferi JD1. We are grateful to the Health and Safety Executive (HSE) for funding M.A.L. and to the Department of the Environment for funding I.P.T.

\section{References}

Austin, B. \& Priest, F. (1986). Modern Bacterial Taxonomy, p. 98. Van Nostrand Reinhold, UK.

BARBOUR, A. G. (1984). Isolation and cultivation of lyme disease spirochaetes. Yale Journal of Biology and Medicine 57, 521-525.

Bailey, M. J., Penn, C. W. \& Cockayne, A. (1985). Evidence for the presence of lipopolysaccharide in Treponema phagedensis (biotype Reiterii) but not Treponema pallidum (Nichols Virulent Strain). FEMS Microbiology Letters 27, 117-121.

Boerlin, P., Peter, O., Bretz, A. G., Postic, D., Baranton, G. \& PIfFARETTI, J.C. (1992). Population genetic analysis of Borrelia burgdorferi by multilocus enzyme electrophoresis. Infection and Immunity 60, 1677-1683.

Cacciopuoti, B., Ciceroni, L. \& Attard Barbini, D. (1991). Fatty acid profiles - a chemotaxonomic key for classification of strains of the Leptospiraceae. International Journal of Systematic Bacteriology 41, 294-300.

Canale-Parola, E. (1991). Free living saccharolytic spirochetes: the genus Spirochaeta. In The Prokaryotes: a Handbook on the Biology of Bacteria Ecophysiology, Isolation, Identification, Applications, 2nd edn, pp. 591-606. Edited by A. Ballows, H. G. Truper, M. Dworkin, W. Harder \& K. H. Schleifer. Berlin, London: Springer-Verlag.

DRUCKER, D. B. (1976). Gas liquid chromatographic chemotaxonomy. Methods in Microbiology 9, 51-125.

Ellinghausen, H. C. \& MCCullogh, W. G. (1965). Nutrition of Leptospira pomona and growth of 13 other serotypes. A serum free medium employing oleic albumin complex. American Journal of Veterinary Research 26, 45-51.

Galanos, C., Luderitz, O., Rietschel, E. T. \& WestPhal, O. (1977). Newer aspects of the chemistry and biology of bacterial lipopoly- saccharide with special reference to their lipid A component. International Review of Biochemistry: Biochemistry of Lipids II, vol. 14, pp. 239-335. Edited by T. W. Goodwin. Baltimore: University Park Press.

Johnson, R. C., Hyde, F. W. \& Rumpel, C. M. (1984). Taxonomy of the Lyme disease spirochaetes. Yale Journal of Biology and Medicine 57, 529-537.

Joseph, R., Holt, S. \& Canale-Parola, E. (1973). Peptidoglycan of free-living anaerobic spirochaetes. Journal of Bacteriology 115 , 426-435.

KELLY, R. T. (1984). Spirochetales. In Bergey's Manual of Systematic Bacteriology, vol. 1, pp. 57-61. Edited by N. R. Krieg \& J. G. Holt. Baltimore: Williams \& Wilkins.

Kent, K. A., Lemcke, R. M. \& Lysons, R. J. (1988). Production, purification and molecular weight determination of the haemolysin of Treponema hyodysenteriae. Journal of Medical Microbiology 27, 215-224.

KlOEPPER, J. W., RODRigo, R., MCINROY, J. A. \& Young, R. W. (1992). Rhizosphere bacteria antagonistic to soybean cyst (Heterodera glycines) and root knot (Meloidogyne incognita) nematodes: identification by fatty acid analysis and frequency of biological control activity. Plant and Soil 139, 75-84.

Kondo, E. \& Ueta, N. (1972). Composition of fatty acids and carbohydrates in Leptospira. Journal of Bacteriology 110, 459-467.

Lane, R. S., Piesman, J. \& Burgdorfer, W. (1991). Lyme Borreliosis: relation of its causative agent to its vectors and hosts in North America and Europe. Annual Review of Entomology 36, 587-609.

LeChEVAlier, M. P. (1977). Lipids in bacterial taxonomy. A taxonomist's view. Critical Reviews in Microbiology 5, 109-210.

LeSCHINE, S. B. \& CANALE-PAROla, E. (1986). Rifampin-resistant RNA polymerase in spirochaetes. FEMS Microbiology Letters 35, 199-204.

MARCONI, R. T. \& GARON, C. F. (1992a). Identification of a third genomic group of Borrelia burgdorferi through signature nucleotide analysis and $16 \mathrm{~S}$ rRNA sequence determination. Journal of General Microbiology 138, 533-536.

Marconi, R. T. \& Garon, C. F. (1992b). Phylogenetic analysis of the genus Borrelia: a comparison of North American and European isolates of Borrelia burgdorferi. Journal of Bacteriology 174, 241-244.

Matrhews, H. M., Yang, T. K. \& Jenkin, H. M. (1979). Unique lipid composition of Treponema pallidum (Nichols Virulent Strain). Infection and Immunity 24, 713-719.

Moribayashi, A., Goto, N., Arimitsu, Y., Himeno, K. \& TAtsuki, S. (1991). Lipids and fatty acids of Leptospira interrogans serovar copenhageni virulent strain Shibaura. Japanese Journal of Medical Science and Biology 44, 87-97.

Mukwaya, G. M. \& Welch, D. F. (1989). Subgrouping of Pseudomonas cepacia by cellular fatty acid composition. Journal of Clinical Microbiology 27, 2646-2649.

Nuessen, M. E., Birmingham, J. R. \& Joens, L. A. (1982). Biological activity of a lipopolysaccharide extracted from Treponema hyodysenteriae. Infection and Immunity 37, 138-142.

Paster, B. J. \& Canale-Parola, E. (1980). Involvement of periplasmic fibrils in the motility of spirochaetes. Journal of Bacteriology 141, 359-364.

Paster, B. J., Stackebrandt, E., Hespell, R. B., Hahn, C. M. \& WoESE, C. R. (1984). The phylogeny of the spirochaetes. Systematic and Applied Microbiology 5, 337-351.

Paster, B. J., Dewhirst, F. E., Weisburg, W. G., Tordoff, L. A., Fraser, G. J., Hespell, R. B., Stanton, T. B., Zablen, L., ManDELCO, L. \& WOESE, C. R. (1991). Phylogenetic analysis of the spirochaetes. Journal of Bacteriology 173, 6101-6109.

Postic, D., Edlinger, C., Richaud, C., Grimont, F., Dufresne, Y., Perolate, P., Baranton, G. \& Grimont, P. A. D. (1990). Two genomic species in Borrelia burgdorferi. Research in Microbiology 141, 465-475.

Rietschel, E. T., Schade, U., Jensen, M., Wollenweber, H. W., LUDERITZ, O. \& GReisMAN, S. G. (1982). Bacterial endotoxins: chemical structure, biological activity and role in septicaemia. Scandanavian Journal of Infectious Diseases supplement 31, 8-21.

SNeAth, P. H. A. \& SoKal, R. R. (1973). Numerical Taxonomy: the 
Principles and Practice of Numerical Classification, pp. 230-234. San Francisco: W. H. Freeman

Stanton, T. B., Jensen, N. S., Casey, T. A., Tordoff, L. A., DewHIRST, F. E. \& PASTER, B. J. (1991). Reclassification of Treponema hyodysenteriae and Treponema innocens in a new genus Serpula gen. nov. as Serpula hyodysenteriae comb. nov. and Serpula innocens comb. nov. International Journal of Systematic Bacteriology 41, $50-58$.

Stead, D. E., Sellwood, J. E., Wilson, J. \& Viney, I. (1992). Evaluation of a commercial microbial identification system based on fatty acid profiles for rapid identification of plant pathogenic bacteria. Journal of Applied Bacteriology 72, 315-321.
Takayama, K., Rothenberg, R. J. \& Barbour, A. G. (1987). Absence of lipopolysaccharide in the lyme disease spirochaete Borrelia burgdorferi. Infection and Immunity 55, 2311-2313.

Thompson, I. P., Bailey, M. J., Ellis, R. J. \& Purdy, K. J. (1993). Subgrouping of bacterial populations by cellular fatty acid composition. FEMS Microbiology Ecology, in the Press.

VINH, T., AdLER, B. \& FAINE, S. (1986). Ultrastructure and chemical composition of lipopolysaccharide extracted from Leptospira interrogans serovar copenhageni. Journal of General Microbiology 132, 103-109.

WeLCH, D. (1991). Applications of cellular fatty acid analysis. Clinical Microbiological Reviews 4, 422-438. 